\title{
Preoperative Videourodynamic Study Is Helpful in Predicting Long-term Postoperative Voiding Function in Asymptomatic Patients With Closed Spinal Dysraphism
}

\author{
Louis Kim ${ }^{1}$, Minh Tung Do ${ }^{1}$, Hyuk Dal Jung, Young Jae $\mathrm{Im}^{1}$, Kyu Chang Wang ${ }^{2}$, Ji Yeon Lee ${ }^{3}$, Kwanjin Park \\ ${ }^{1}$ Department of Urology, Seoul National University Children's Hospital, Seoul National University, College of Medicine, Seoul, Korea \\ ${ }^{2}$ Neuro-oncology Clinic, Center for Rare Cancers, National Cancer Center, Goyang, Korea \\ ${ }^{3}$ Department of Neurosurgery, Seoul National University Hospital, Seoul National University College of Medicine, Seoul, Korea
}

Purpose: Controversy exists regarding the role preoperative urodynamic study for asymptomatic closed spinal dysraphism as it has failed to reveal the benefit in surgical decision and expectation of urological outcomes. We explore the relationship between preoperative videourodynamic study and postoperative urological outcomes after toilet training completed, focusing on their capability of spontaneous voiding.

Methods: We retrospectively reviewed the data of 181 patients who underwent preventive spinal cord untethering and followed at least till the completion of toilet training. Before untethering, patients underwent preoperative videourodynamic study. Postoperative voiding function was evaluated in 3 phases: (1) till postoperative 6 months, (2) till the completion of toilet training, and (3) 2 years after toilet training. Changing distribution of emptying pattern at each period was described. Also, relevance to preoperative urodynamic parameters on spontaneous voiding and urinary continence after toilet training was assessed.

Results: Spinal lipoma and low lying conus were found in 145 (80\%) and 128 patients (70.7\%), respectively. Spontaneous voiding was found in 125 (69.1\%), 164 (90.6\%), and 162 patients (89.5\%) at postoperative 6 months, till the toilet training, and 2 years after toilet training, respectively. Videourodynamics helped to clarify the presence of vesicourethral synergy. This was correlated with spontaneous voiding at postoperative 6 months and better urinary continence after 2 years of toilet training. Conclusions: Eventual spontaneous voiding was achieved till toilet training in $90 \%$ patients following preventive untethering. Those showing preoperative vesicourethral synergy was associated with faster achievement of spontaneous voiding and better urinary continence when they enter elementary school.

Keywords: Urodynamics studies; Occult spinal dysraphism; Prophylactic surgery; Voiding characteristics; Tethering; Toilet training

- Research Ethics: The study was approved by the Institutional Review Board (IRB) of Seoul National University Hospital (IRB No. 1809-029-

969).

- Conflict of Interest: No potential conflict of interest relevant to this article was reported.

Corresponding author: Kwanjin Park (1D https://orcid.org/0000-0002-8926-3047 Department of Urology, Seoul National University Children's Hospital, Seoul National University College of Medicine, 101 Daehak-ro, Jongro-gu, Seoul 03080, Korea

Email: urodori@naver.com

Submitted: August 11, 2021 / Accepted after revision: November 14, 2021
This is an Open Access article distributed under the terms of the Creco
commons.org/licenses/by-nc/4.0/) which permits unrestricted non-commercial use, distribution, and reproduction in any medium, provided the original work is properly cited. 


\section{INTRODUCTION}

Spinal dysraphism (SD) is an umbrella term referring to the group of the congenital spine and spinal cord defects and can be classified into open and closed types. Both of them may cause neurogenic bladder (NB) through the main mechanism of tethered cord syndrome (TCS), though the odds for the development of NB are smaller for the latter [1]. Recent improved perinatal screening tests reveal increasing number of closed SD without evidence for TCS. Surgical indication for this group of patients has not been standardized, while most surgeons would agree that not all patients require preventive surgery.

When patients are affected by TCS, one of the most common and unwanted complications would be loss of volitional spontaneous voiding, which could lead to urinary incontinence and the necessity of clean intermittent catheterization (CIC). To prevent the development or to halt the progression of TCS, spinal cord untethering (SCU) is contemplated since some neurologic deficits become irreversible once urological or neuroorthopedic deteriorations become evident [2-4]. For those who are asymptomatic indicating those without overt neurological problems, the aim of SCU is prevention from functional loss, whereas for those with signs of neurologic abnormalities, the purpose of SCU should be therapeutic to halt the progressive deterioration and possibly to save neurological damage. Preoperative urodynamic study (UDS) can be performed to examine the presence of occult urological problems attributed to TCS or to assess the severity of these problems in case of obvious urological deterioration.

Meanwhile, performing and interpreting UDS for infants with suspicious TCS is challenging even in experienced urologists. Given poor verbal communication in all patients, up to $1 / 3$ of children were said to be uncooperative during the UDS [5]. To circumvent this nonphysiological situation, performing UDS under placement of suprapubic catheter or sedation can be considered. This also appears invasive and could adversely affect some urodynamic parameters. In addition, interpretation of UDS is also problematic. abnormal neurologic findings such as detrusor overactivity (DO) or detrusor sphincter dyssynergia (DSD) can be seen in neurologically normal children [6]. Moreover, such findings are often ambiguous unlike the case for overt neurologic lesions like spinal cord injury. Managing pre-toilettrained children is not easy and they would not void in the presence of catheter without overt neurologic lesions. Limited urodynamic data for this age are available and no urodynamic finding has not been accepted as pathognomonic to TCS.

Up to now, dozens of studies have described the urodynamic changes following SCU and attempted to reveal the role of preoperative UDS. Some detected abnormal bladder functions, others reported changes in urodynamic variables following SCU, though parameters that were reported to undergo changes after SCU were not consistent between them [2,4,5,7-17]. This was at least partially due to the fact that most studies compared single postoperative UDS performed in various postoperative periods with preoperative one, ignoring the possibility of developing bladder function in children. Thus, inclusion of urodynamic data performed regular postoperative periods would be more ideal but this is impractical and sometimes too invasive to most patients with normal spontaneous voiding. Based on our experience, applying regular UDS in these patients may be encountered noncompliance in substantial number of patients.

To address this issue, we devised noninvasive follow-up protocol utilizing portable ultrasound bladder scanner. Sparing UDS only for those with abnormal postvoid residual (PVR) volume could save required number of follow-up UDS substantially. As most of patients achieved toilet training (TT) with spontaneous voiding and became continent, this could be regarded as normal voiding function and surrogate long-term outcome that every SCU want to get. Association with preoperative urodynamic data would reveal important preoperative urodynamic findings relevant to normal voiding.

Therefore, the main objective of this study was to reveal important preoperative urodynamic findings relevant to good long-term outcomes. In addition, changing pattern of spontaneous voiding and requirement of CIC will be longitudinally described. This would be important data for counselling and follow-up of such patients.

\section{MATERIALS AND METHODS}

\section{Data Collection}

This was a retrospective observational study of 219 patients with SD, who received the SCU at a tertiary children's hospital from January 2009 to December 2016. The inclusion criteria were as follows: (1) received the diagnosis of congenital closed spinal dysaraphism without the overt evidence for neurological deterioration and performed preventive SCU at our hospital; (2) underwent preoperative videourodynamic study (VUDS); (3) were followed at least till the completion of TT. Data of 38 
patients who showed neuroorthopedic signs of TCS or urodynamic evidences for NB were not included in analysis. After all, a total of 181 patients were included in the final analysis. The study was approved by the Institutional Review Board (\#1809029-969) before the commencement.

\section{Determination of SCU}

Our neurosurgeons decide to perform preventive untethering in case of (1) significantly lower-lying conus medullaris (below L3), (2) increased amount of syrinx, (3) presence of intradural lipoma (not a filar lipoma), and (4) high-risk SD for deterioration (cutaneous dermal sinus, hemangioma, or split cord malformation). Before SCU, neurosurgeons referred patients to urology for preoperative evaluation with VUDS.

\section{Videourodynamic Study}

All VUDS was performed following the International Children's Continence Society recommendation [18]. Usually, no anesthesia was applied in patients less than 9 months old and cooperative patients. While the presence of parents, distracting toys or watching YouTube were helpful for stabilizing children, some patients required sedation due to significant anxiety or agitation during the procedure, which could adversely affect the performance and interpretation. The patients received either oral midazolam or intravenous dexmedetomidine under the surveillance of pediatric anesthesiologists at the time of insertion of catheter. It was reported that sedation for catheter placement does not impair the quality of spontaneous voiding $[19,20]$ though this could not guarantee that the use of medication did not affect the quality of UDS.

Prior to cystometry, measurement of PVR urine was first attempted with portable ultrasound scanner. During cystometry, bladder was gradually filled until either the start of voiding or reaching $130 \%$ of estimated bladder capacity at rates adjusted to $5 \%-10 \%$ of estimated bladder capacity. In those with the inability to void, the bladder was considered to reach its full capacity when patients became intolerable due to discomfort or experienced continuous leakage, or end filling pressure was steadily over $30 \mathrm{~cm} \mathrm{H}_{2} \mathrm{O}$. During the storage phase following parameters were measured and evaluated: compliance, cystometric capacity, end filling pressure for those who failed show spontaneous voiding, DO, presence of vesicoureteral reflux (VUR) and DSD. Significant DO was defined when multiple or single episodes of discernible (more than $15 \mathrm{~cm} \mathrm{H}_{2} \mathrm{O}$ ) idiopathic detrusor activities before reaching cystometric capacity. During void- ing with noticeable detrusor activity, synergy was defined as funneling of bladder neck and opening of urethra. On the other hand, DSD was defined as active sphincteric movement in the face of elevating detrusor pressure. It is often associated with dilated posterior urethra or concomitant sphinteric activity of surface perineal electromyography (EMG). Reduced bladder compliance was defined when the calculated compliance at capacity was less than $10 \mathrm{~mL} / \mathrm{cm} \mathrm{H}_{2} \mathrm{O}$. VUR found during the study was also recorded.

Gradual opening of the bladder neck during filling phase of VUDS and decreased anal tone during placement of rectal catheter were recorded as potential markers of neurologic deficit relevant to TCS [17]. Decreased anal tone was defined as ability of insertion of fingertip with minimal resistance.

While synergic voiding with detrusor activity is easy to discern, DSD was sometimes difficult to determine. No patient showed typical DSD associated with hyperactivity of perineal surface EMG. Instead, they presented lack of funneling of bladder neck or closing action of urethra as opposed to funneling seen in vesicourethral synergy (Fig. 1). This was confirmed by comparison of sequential changes of sphincteric zone during VUDS. As we were not convinced that this nonsynergic movement of sphincter were actual DSD seen in NB, this phenomenon was described as 'lack of synergy'.

After 100\%-130\% of bladder filling according to estimated capacity, we waited at least for 20 minutes till the commencement of voiding. When there was no demonstration of voiding, patients were allowed to void without catheter and PVR was again measured. Without the history of continuous wetting and evidence of incompetent urethral sphincter during VUDS, normal PVR was assumed to be indirect evidence for synergic spontaneous voiding. Patients with persistently high PVR even after multiple voiding attempts and showing aforementioned sphincteric movement was designated 'lack of synergy' suggestive of DSD due to presence of occult TCS.

\section{Protocols for Urologic Evaluation and Follow-up}

Following successful SCU, most children showed spontaneous voiding with normal PVR. Apart from aforementioned parental reluctance in performing regular follow-up UDS, preforming UDS was even more challenging because of intact pain sense during catheterization and limited verbal communication. Sometimes, they would often not void in the presence of catheter not to mention difficulty in placing catheter. Thus, we followed them with noninvasive PVR measurement and spared 

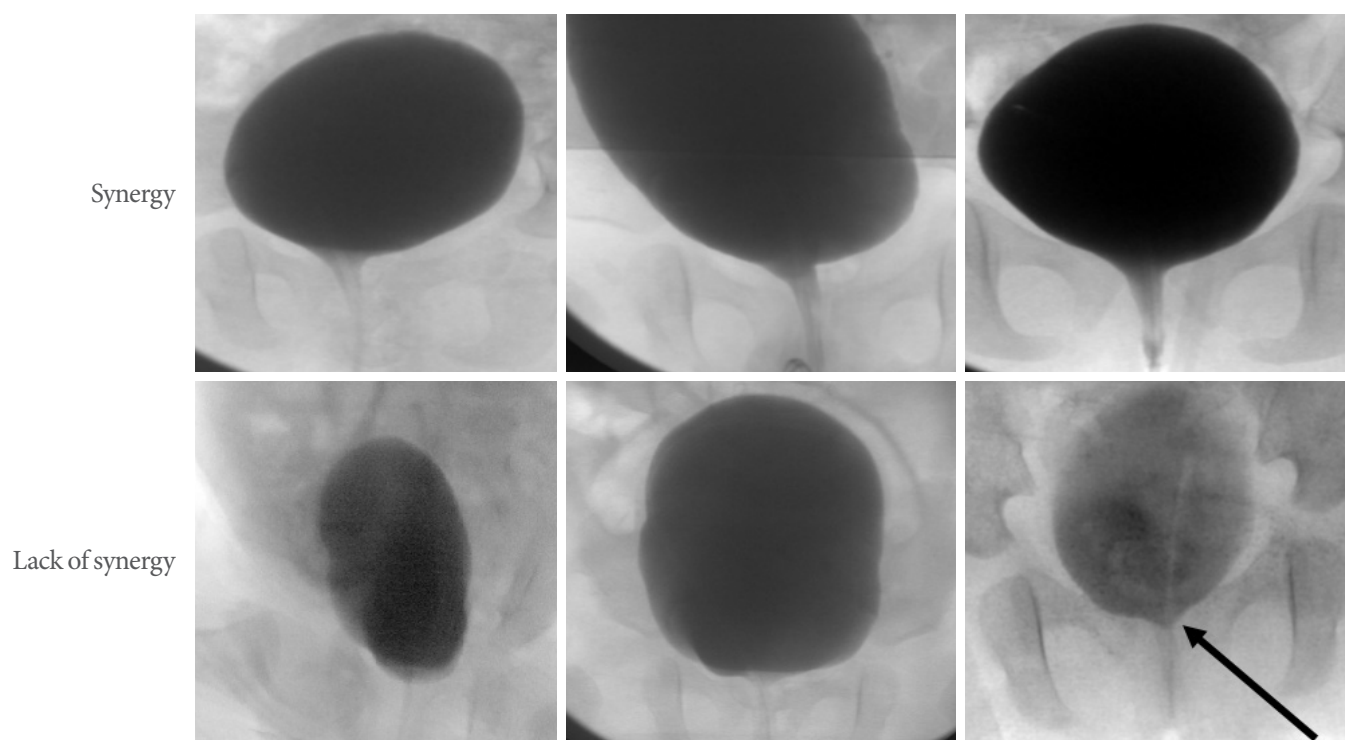

Fig. 1. Typical pattern of videourodynamic findings of vesicourethral synergy. Upper panel indicates synergy in 3 individual patients and lower panel indicates lack of synergy. Vesicourethral synergy typically shows funneling of bladder neck and active dilation of urethra whereas lack of synergy revealed failure of funneling of bladder neck and passive opening of urethra in the face of increasing vesical pressure. Sometimes, dyssynergic active closure of sphincter (arrow), characteristic of detrusor sphincter dyssynergia was seen.

UDS in case of (1) persistently elevated PVR or (2) recurrent episodes of foul odor urine, hematuria, or fever suggestive of urinary tract infection or (3) persistent wetting despite the proper management.

During PVR measurement, parents were requested to see whether diaper might be wet in every 30 minutes and ultrasound bladder scanner was applied as soon as confirming wet diaper. If the measured PVR was more than $20 \%$ of age-adjusted estimated bladder capacity, patients were asked for another session of the measurement whether it became normalized with repetitive attempt. The resultant lowest measured volume was recorded to be PVR of the patients.

Following SCU, the need for CIC was determined based on PVR measurement. In those who were capable of spontaneous voiding, they usually followed every 3-6 months with PVR measurement until TT, and the follow-up was extended to annually once they were adequately toilet trained. Our practical definition of TT was no requirement of regular diaper at their daily life. Achievement of TT can be regarded as maturation in terms of voiding function. Thus, postoperative voiding function was separately evaluated in 3 phases: (1) up to postoperative 6 months, (2) till the completion of TT, and (3) 2 years after TT when children usually enter school. Renal and bladder ultrasound was conducted annually.

\section{Statistical Analysis}

Descriptive statistics were performed to summarize clinical characteristics as well as urodynamic parameters. Continuous variables and categorical variables were described as mean \pm standard deviation and percent to the total number, respectively. The chi-square and t-test were performed to compare the differences in continuous and categorical variables, respectively. Multivariate logistic regression analysis was performed to confirm the association between preoperative VUDS parameters and long-term outcomes including spontaneous voiding and urinary incontinence. A P-value of less than 0.05 will be considered statistically significant.

\section{RESULTS}

Clinical and urodynamic features were depicted in Table 1 . The mean age at preoperative UDS and SCU was 5.6 and 6 months, respectively. Approximately $80 \%$ and $70 \%$ of patients were reported to have intraspinal lipoma and lower-lying conus respectively. Measurement of PVR and VUDS revealed that 139 (76.8\%), 156 (86.2\%), and 172 patients (95\%) showed findings of normal PVR, compliance, and synergy, respectively. Patients achieved TT at the mean of 43 months and their mean followup periods was 92 months (72-134 months). Sedation was required in 58 patients (32\%). Comparison of those receiving se- 
Table 1. Patient clinical characteristics and preoperative urodynamic findings

\begin{tabular}{|c|c|}
\hline Characteristic & Value \\
\hline Age at UDS (mo) & $5.6 \pm 6.5(0-40)$ \\
\hline Age at SCU (mo) & $6.0 \pm 8.0(1-44)$ \\
\hline \multicolumn{2}{|l|}{ Sex } \\
\hline Male & $80(44.2)$ \\
\hline Female & $101(55.8)$ \\
\hline \multicolumn{2}{|l|}{ Diagnosis } \\
\hline Lipoma & $149(82.3)$ \\
\hline Tethered cord syndrome & $32(17.7)$ \\
\hline \multicolumn{2}{|l|}{ Conus Level } \\
\hline L2-3 & $33(18.2)$ \\
\hline L3-4 & $34(18.8)$ \\
\hline Below L5 & $114(63)$ \\
\hline \multicolumn{2}{|l|}{ Syringomyelia } \\
\hline Present & $35(19.3)$ \\
\hline Absent & $146(80.7)$ \\
\hline \multicolumn{2}{|l|}{ Electromyography } \\
\hline Normal & $158(87.3)$ \\
\hline Abnormal & $19(10.5)$ \\
\hline Incomplete & $4(2.2)$ \\
\hline Time to $\mathrm{TT}^{\mathrm{a})}(\mathrm{mo})$ & $43.0 \pm 17.2(21-68)$ \\
\hline \multicolumn{2}{|c|}{ Preoperative urodynamic findings } \\
\hline \multicolumn{2}{|l|}{ Residual volume ${ }^{\text {b) }}$} \\
\hline$<20 \%$ & $139(76.8)$ \\
\hline$\geq 20 \%$ & $42(23.2)$ \\
\hline \multicolumn{2}{|l|}{ Anal tone } \\
\hline Competent & $139(76.8)$ \\
\hline Incompetent & $42(23.2)$ \\
\hline \multicolumn{2}{|l|}{ Bladder neck } \\
\hline Closed & $104(57.5)$ \\
\hline Open & $77(42.5)$ \\
\hline \multicolumn{2}{|l|}{ Compliance } \\
\hline$\geq 10 \mathrm{~mL} / \mathrm{cm} \mathrm{H}_{2} \mathrm{O}$ & $156(86.2)$ \\
\hline$<10 \mathrm{~mL} / \mathrm{cm} \mathrm{H}_{2} \mathrm{O}$ & $25(13.8)$ \\
\hline \multicolumn{2}{|l|}{ Vesicourethral synergy } \\
\hline Synergic & $172(95)$ \\
\hline Lack of synergy & $9(5)$ \\
\hline \multicolumn{2}{|l|}{ Detrusor overactivity } \\
\hline Yes & $25(13.8)$ \\
\hline No & $156(86.2)$ \\
\hline
\end{tabular}

(continued)
Table 1. Patient clinical characteristics and preoperative urodynamic findings (continued)

\begin{tabular}{lr}
\hline Characteristic & Value \\
\hline Small capacity $^{c}$ & \\
Yes & $38(21)$ \\
No & $143(79)$ \\
\hline
\end{tabular}

Values are presented as mean \pm standard deviation (range) or number (\%).

UDS, urodynamic study; SCU, spinal cord untethering.

a) TT, toilet training-under the name of tethered cord syndrome, 6 patients with dermal sinus, 3 patients with hemangioma, 7 patients with limited dorsal myeloschisis, 7 patients with low-lying conus, 3 patients with syringomyelia, 2 patients terminal myelocystocele and 4 patients

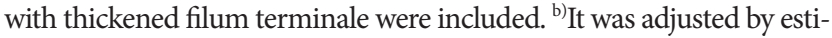
mated capacity for age. ${ }^{c}$ It was defined as less than $70 \%$ of estimated age-adjusted capacity.

dation and those not revealed significantly lower incidence of DO and higher cystometric capacity while other urodynamic parameters were comparable (data are not shown).

Fig. 2 showed distribution of emptying pattern at each time points with regards to the presence of synergy. Until 6 months of SCU, 123 patients (71.5\%) of preoperative synergy were capable of spontaneous voiding with normal PVR, on the other hand, during the same period, spontaneous voiding was seen in 2 out of 9 patients $(22.2 \%)$ who showed lack of synergy. Until the TT, 39 patients (22.6\%) and 5 patients (55.6\%) with and without preoperative synergy, respectively achieved spontaneous voiding. Two years after TT, no delayed achievement of spontaneous voiding was observed. Conversely, 2 patients became deteriorated and required CIC. Of 19 patients eventually required CIC, 11 patients were diagnosed secondary TCS and received reoperation for secondary TCS.

Tables 2 and 3 showed the univariate and multivariate analysis, respectively between preoperative urodynamic parameters and postoperative spontaneous voiding and continence after TT. Only synergy was associated with restoration of spontaneous voiding until 6 months of SCU and urinary continence after TT.

\section{DISCUSSION}

This study was conducted to clarify the role of preoperative VUDS in asymptomatic closed SD patients at risk of future TCS. Though all patients were asymptomatic, their clinical features are reported to harbor more than $60 \%$ and $80 \%$ risk of 


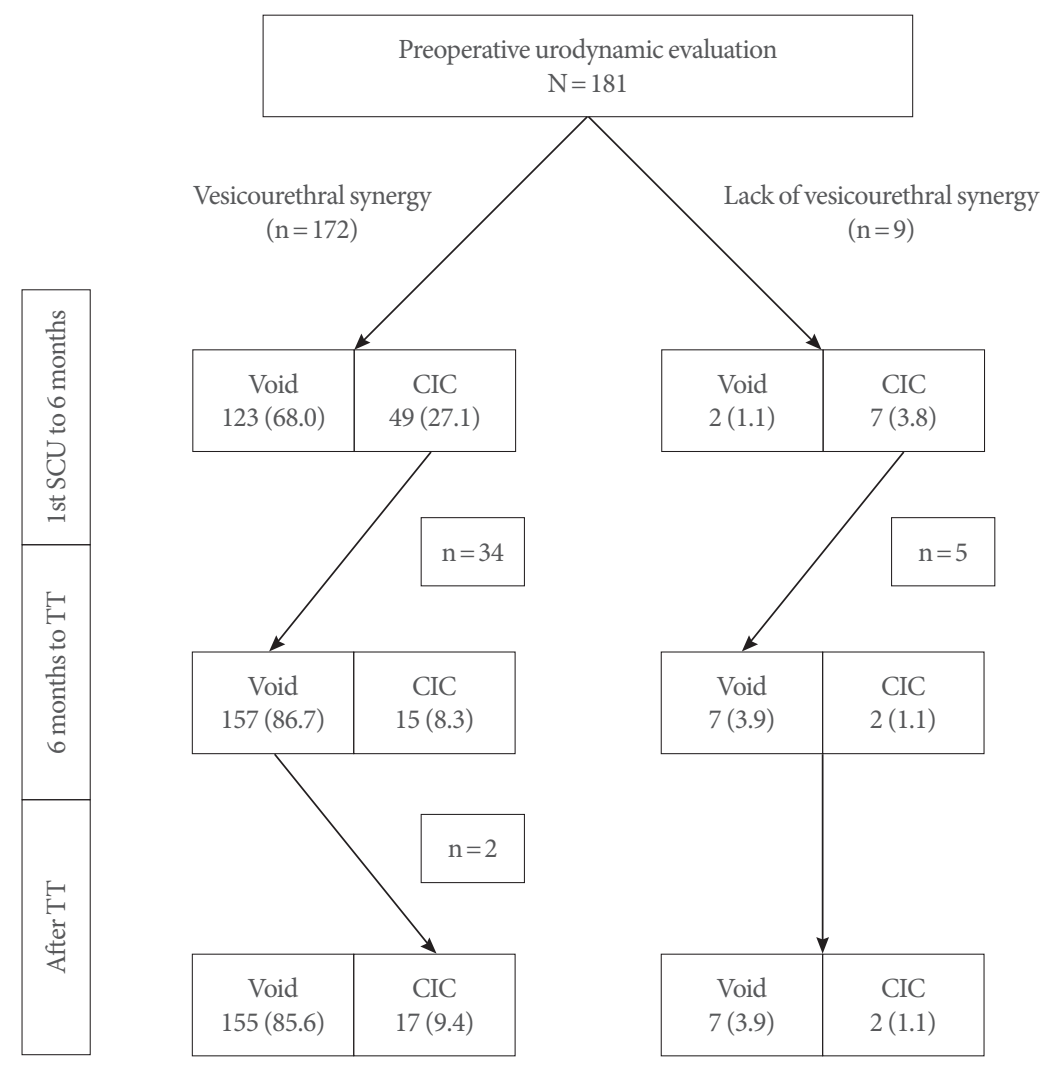

Fig. 2. Changing patients' distribution of voiding status according to vesicourethral synergy. Evaluation was made at 2 time points of 6 months after spinal cord untethering and toilet training. Changes in voiding status was indicated with arrows. Void, spontaneous voiding; CIC, clean intermittent catheterization; SCU, spinal cord untethering; TT, toilet training.

urological and urodynamic deterioration if they receive no treatment [21]. Exclusion of overtly symptomatic cases suggested the purpose of SCU is preventive and this contrasted to previous studies including mixture of symptomatic cases.

We have first attempted correlation of preoperative urodynamic parameters with long-term clinical variables like spontaneous voiding or incontinence at the time of TT or after 2 years of TT. This is more feasible than comparing with those of single postoperative UDS, considering aforementioned reduced compliance as reported by Broderick et al. [5] Furthermore, continuing maturation of bladder function would confuse the interpretation.

For the first time, changing distribution of spontaneous voiding during long-term follow-up revealed several important results: (1) Preoperative VUDS help to predict immediate recovery of spontaneous voiding; (2) Regardless of preoperative UDS, 70\% patients who initially failed to show spontaneous voiding slowly achieve spontaneous voiding and this occurred until TT; (3) About 90\% patients will achieve eventual sponta- neous voiding. Synergy in preoperative UDS may indicate intact reflex arc facilitating immediate recovery. This could be useful guide to refer in following-up patients after preventive SCU. Also, it should be borne in mind that about a third of patients required CIC until 6 months of SCU. Notably, compared to those lacking preoperative synergy, early achievement of spontaneous voiding was seen about $70 \%$ of those with preoperative synergy.

On the other hand, further follow-up of more than 6 months observed delayed achievement of spontaneous voiding in about $70 \%$ patients who had failed to achieve spontaneous voiding until the 6 months of SCU. This delayed achievement has not been reported before. Based on the fact that this achievement was seen in similar rates regardless of preoperative synergy, we speculated the reason may lie in maturation of bladder function which can be expected before the completion of TT. It is also worth mentioning that no further improvement of spontaneous voiding was not seen after TT. Interestingly, the rate of delayed improvement was similar regardless of preoperative syn- 
Table 2. Relationship between urodynamic parameter and voiding characteristics

\begin{tabular}{|c|c|c|c|c|c|c|c|c|c|}
\hline \multirow[b]{2}{*}{ Parameter } & \multicolumn{3}{|c|}{ Postoperative to 6 months } & \multicolumn{3}{|c|}{ After toilet training } & \multicolumn{3}{|c|}{ Urinary continence } \\
\hline & $\begin{array}{l}\text { Spontaneous } \\
\text { voiding }\end{array}$ & $\mathrm{CIC}$ & P-value & $\begin{array}{c}\text { Spontaneous } \\
\text { voiding }\end{array}$ & $\mathrm{CIC}$ & P-value & Continent & Incontinent & P-value \\
\hline PVR (mL) & & & 0.26 & & & 1.0 & & & 1.0 \\
\hline$<20 \%$ & $99(54.7)$ & $40(22.1)$ & & $124(68.5)$ & $15(8.3)$ & & $117(64.6)$ & $22(12.2)$ & \\
\hline$\geq 20 \%$ & $26(14.4)$ & $16(8.8)$ & & $38(21.0)$ & $4(2.2)$ & & $36(19.9)$ & $6(3.3)$ & \\
\hline Anal tone & & & 0.57 & & & 0.57 & & & 0.81 \\
\hline Competent & $94(51.9)$ & $45(24.9)$ & & $123(68.0)$ & $16(8.8)$ & & $118(65.2)$ & $21(11.6)$ & \\
\hline Incompetent & $31(17.1)$ & $11(6.1)$ & & $39(21.5)$ & $3(1.7)$ & & $35(19.3)$ & $7(3.9)$ & \\
\hline Compliance & & & 0.64 & & & 0.73 & & & 0.77 \\
\hline$\geq 10 \mathrm{~mL} / \mathrm{cm} \mathrm{H}_{2} \mathrm{O}$ & $109(60.2)$ & $47(26.0)$ & & $140(77.3)$ & $16(8.8)$ & & $131(72.4)$ & $25(13.8)$ & \\
\hline$<10 \mathrm{~mL} / \mathrm{cm} \mathrm{H}_{2} \mathrm{O}$ & $16(8.8)$ & $9(5.0)$ & & $22(12.2)$ & $3(1.7)$ & & $22(12.2)$ & $3(1.6)$ & \\
\hline Bladder neck & & & 0.52 & & & 0.34 & & & 0.68 \\
\hline Closed & $74(40.9)$ & $30(16.6)$ & & $91(50.3)$ & $13(7.2)$ & & $89(49.2)$ & $15(8.3)$ & \\
\hline Open & $51(28.2)$ & $26(14.3)$ & & $71(39.2)$ & $6(3.3)$ & & $64(35.4)$ & $13(7.1)$ & \\
\hline Detrusor overactivity & & & 1.00 & & & 1.00 & & & 0.55 \\
\hline Normal & $108(59.7)$ & $48(26.5)$ & & $139(76.8)$ & $17(9.4)$ & & $133(73.5)$ & $23(12.7)$ & \\
\hline Overactive & $17(9.4)$ & $8(4.4)$ & & $23(12.7)$ & $2(1.1)$ & & $20(11.0)$ & $5(2.8)$ & \\
\hline Small capacity & & & 0.92 & & & 0.77 & & & 1.00 \\
\hline Normal & $99(54.7)$ & $44(24.3)$ & & $127(70.2)$ & $16(8.8)$ & & $121(66.9)$ & $22(12.2)$ & \\
\hline Small & $26(14.4)$ & $12(6.6)$ & & $35(19.3)$ & $3(1.7)$ & & $32(17.7)$ & $6(3.3)$ & \\
\hline Vesicourethral synergy & & & 0.004 & & & 0.24 & & & 0.03 \\
\hline Synergy & $123(68.0)$ & $49(27.1)$ & & $155(85.6)$ & $17(9.4)$ & & $148(81.8)$ & $24(13.3)$ & \\
\hline Dyssynergy & $2(1.1)$ & $7(3.8)$ & & $7(3.9)$ & $2(1.1)$ & & $5(2.8)$ & $4(2.2)$ & \\
\hline
\end{tabular}

Values are presented as number (\%).

CIC, clean intermittent catheterization; PVR, postvoid residual urine.

Table 3. Multivariate logistic regression of voiding characteristics and urinary continence

\begin{tabular}{|c|c|c|c|c|c|c|}
\hline \multirow{3}{*}{ Parameter } & \multicolumn{4}{|c|}{ Spontaneous voiding } & \multirow{2}{*}{\multicolumn{2}{|c|}{ Urinary continence }} \\
\hline & \multicolumn{2}{|c|}{ Postoperative to 6 months } & \multicolumn{2}{|c|}{ After toilet training } & & \\
\hline & OR & $95 \% \mathrm{CI}$ & OR & $95 \% \mathrm{CI}$ & OR & $95 \% \mathrm{CI}$ \\
\hline PVR & 1.52 & $(0.71-3.27)$ & 0.91 & $(0.28-3.01)$ & 0.76 & $(0.27-2.15)$ \\
\hline Anal tone & 0.63 & $(0.27-1.46)$ & 0.56 & $(0.14-2.21)$ & 1.25 & $(0.46-3.43)$ \\
\hline Compliance & 1.28 & $(0.49-3.35)$ & 1.51 & $(0.36-6.27)$ & 0.58 & $(0.15-2.27)$ \\
\hline Bladder neck & 1.29 & $(0.66-2.52)$ & 0.60 & $(0.21-1.69)$ & 1.29 & $(0.56-2.97)$ \\
\hline Detrusor overactivity & 1.19 & $(0.47-3.09)$ & 0.91 & $(0.19-4.44)$ & 1.69 & $(0.55-5.23)$ \\
\hline Small capacity & 0.99 & $(0.44-2.25)$ & 0.68 & $(0.18-2.57)$ & 0.93 & $(0.33-2.61)$ \\
\hline Vesicourethral synergy & 8.81 & $(1.74-44.59)^{\star}$ & 2.41 & $(0.44-13.2)$ & 6.07 & $(1.44-25.5)^{\star}$ \\
\hline
\end{tabular}

OR, odds ratio; CI, confidence interval; PVR, postvoid residual urine.

${ }^{*} \mathrm{P}<0.05$, statistical significance.

ergy suggesting the common occurrence between those who had not recovered well until 6 months of SCU and those with lack of synergy who had not been recovered immediately from harmful effect of TCS.

Since vesicourethral synergy requires normal coordinative function by pontine micturition center and intact conduction 
of neural signal in spinal cord, loss of synergic voiding could suggest the presence of upper motor neuron lesion affecting this coordination. TCS could elicit upper motor neuron pathology by mechanical traction and subsequent cord ischemia. While both DO and DSD are regarded as upper motor signs suggestive of the presence of TCS, DO can also be found in nonneurogenic etiology. To reveal DSD, fluoroscopic visualization of sphincteric zone was attempted and we described the term "lack of synergy" instead of dyssynergy because the evident dyscoordinating sphincteric movement such as spinning top urethra was rarely evident in such a young and immature patient.

Along with early achievement of spontaneous voiding, preoperative synergy was correlated with continence after TT. Assuming that $\mathrm{SD}$ is structural maldevelopment in spinal cord, it can be speculated that patients are likely to have functional immaturity involving bladder and bowel control. The presence of synergy may suggest better functional integrity than those not.

The limitation of this study should be mentioned. First, because this study was a retrospective study, some clinical information was missing and we could not fully assess the potential effect of pharmacological interventions following SCU, such as anticholinergic or laxatives, as they can impact the storage and emptying function of bladder. Second, unlike other studies which included symptomatic patients and even adult population, our population was rather homogenous population including patients who received preventive SCU. Thus, the data revealed may not be extrapolated to other populations like open SD or symptomatic cases. Third, the use of a sedative agent may affect bladder contractility, as the preclinical study and our data has indicated [22,23]. Nevertheless, given the crucial role of vesicourethral synergy in future urological outcomes, we believe that applying sedation would provide us better view in observing voiding phase than letting patients tossing around with anxiety and agitation [24]. Thus, we advocated judicious use of this technique. Last but not least, our results were based on neurosurgical expertise which has been evolved for years. Thus, our data should be interpreted as such.

In conclusion, no preoperative urodynamic variable was related to capability of long-term spontaneous voiding. Instead, vesicourethral synergy in preoperative urodynamics was helpful to predict early achievement of spontaneous voiding and urinary continence following TT.

\section{AUTHOR CONTRIBUTION STATEMENT}

- Conceptualization: $H D J, K C W, K P$

- Data curation: $L K, M T D, H D J, J Y L, K P$

- Formal analysis: $L K, M T D, K P$

- Methodology: MTD, HDJ, JYL

- Project administration: $Y I$

- Visualization: $K C W$

-Writing-original draft: $L K, K P$

·Writing-review \& editing: MTD, YI, JYL, KCW

\section{ORCID}

$\begin{array}{ll}\text { Minh Tung Do } & 0000-0003-4936-5660 \\ \text { Hyuk Dal Jung } & 0000-0003-3265-1652 \\ \text { Young Jae Im } & 0000-0002-8285-483 X \\ \text { Kyu Chang Wang } & 0000-0001-7440-6650 \\ \text { Kwanjin Park } & 0000-0002-8926-3047\end{array}$

\section{REFERENCES}

1. Peyronnet B, Brochard C, Jezequel M, Hascoet J, Alimi Q, Senal N, et al. Comparison of neurogenic lower urinary tract dysfunctions in open versus closed spinal dysraphism: a prospective cross-sectional study of 318 patients. Neurourol Urodyn 2018;37:2818-26.

2. Atala A, Bauer SB, Dyro FM, Shefner J, Shillito J, Sathi S, et al. Bladder functional changes resulting from lipomyelomeningocele repair. J Urol 1992;148:592-4.

3. Proctor MR, Bauer SB, Scott RM. The effect of surgery for split spinal cord malformation on neurologic and urologic function. Pediatr Neurosurg 2000;32:13-9.

4. Satar N, Bauer SB, Shefner J, Kelly MD, Darbey MM. The effects of delayed diagnosis and treatment in patients with an occult spinal dysraphism. J Urol 1995;154:754-8.

5. Broderick KM, Munoz O, Herndon CD, Joseph DB, Kitchens DM. Utility of urodynamics in the management of asymptomatic tethered cord in children. World J Urol 2015;33:1139-42.

6. Yeung CK, Godley ML, Ho CK, Ransley PG, Duffy PG, Chen CN, et al. Some new insights into bladder function in infancy. Br J Urol 1995;76:235-40.

7. Abrahamsson K, Olsson I, Sillen U. Urodynamic findings in children with myelomeningocele after untethering of the spinal cord. J Urol 2007;177:331-4; discussion 4.

8. Alsowayan O, Alzahrani A, Farmer JP, Capolicchio JP, Jednak R, El-Sherbiny M. Comprehensive analysis of the clinical and urody- 
namic outcomes of primary tethered spinal cord before and after spinal cord untethering. J Pediatr Urol 2016;12:285.e1-285.e5.

9. Dushi G, Frey P, Ramseyer P, Vernet O, Meyrat BJ. Urodynamic score in children with lipomyelomeningocele: a prospective study. J Urol 2011;186:655-9.

10. Geyik M, Geyik S, Sen H, Pusat S, Alptekin M, Yilmaz AE, et al. Urodynamic outcomes of detethering in children: experience with 46 pediatric patients. Childs Nerv Syst 2016;32:1079-84.

11. Gross AJ, Michael T, Godeman F, Weigel K, Huland H. Urological findings in patients with neurosurgically treated tethered spinal cord. J Urol 1993;149:1510-1.

12. Guerra LA, Pike J, Milks J, Barrowman N, Leonard M. Outcome in patients who underwent tethered cord release for occult spinal dysraphism. J Urol 2006;176:1729-32.

13. Hsieh MH, Perry V, Gupta N, Pearson C, Nguyen HT. The effects of detethering on the urodynamics profile in children with a tethered cord. J Neurosurg 2006;105(5 Suppl):391-5.

14. Kim SW, Ha JY, Lee YS, Lee HY, Im YJ, Han SW. Six-month postoperative urodynamic score: a potential predictor of long-term bladder function after detethering surgery in patients with tethered cord syndrome. J Urol 2014;192:221-7.

15. Macejko AM, Cheng EY, Yerkes EB, Meyer T, Bowman RM, Kaplan WE. Clinical urological outcomes following primary tethered cord release in children younger than 3 years. J Urol 2007;178:1738-42; discussion 42-3.

16. Metcalfe PD, Luerssen TG, King SJ, Kaefer M, Meldrum KK, Cain MP, et al. Treatment of the occult tethered spinal cord for neuropathic bladder: results of sectioning the filum terminale. J Urol
2006;176:1826-9; discussion 30.

17. Tseng JH, Kuo MF, Kwang Tu Y, Tseng MY. Outcome of untethering for symptomatic spina bifida occulta with lumbosacral spinal cord tethering in 31 patients: analysis of preoperative prognostic factors. Spine J 2008;8:630-8.

18. Bauer SB, Nijman RJ, Drzewiecki BA, Sillen U, Hoebeke P. International Children's Continence Society standardization report on urodynamic studies of the lower urinary tract in children. Neurourol Urodyn 2015;34:640-7.

19. Stokland E, Andréasson S, Jacobsson B, Jodal U, Ljung B. Sedation with midazolam for voiding cystourethrography in children: a randomised double-blind study. Pediatr Radiol 2003;33:247-9.

20. Zier JL, Kvam KA, Kurachek SC, Finkelstein M. Sedation with nitrous oxide compared with no sedation during catheterization for urologic imaging in children. Pediatr Radiol 2007;37:678-84.

21. Veenboer PW, Bosch JL, van Asbeck FW, de Kort LM. Paucity of evidence for urinary tract outcomes in closed spinal dysraphism: a systematic review. BJU Int 2013;112:1009-17.

22. Ceran C, Pampal A, Goktas O, Pampal HK, Olmez E. Commonly used intravenous anesthetics decrease bladder contractility: an in vitro study of the effects of propofol, ketamine, and midazolam on the rat bladder. Indian J Urol 2010;26:364-8.

23. Xu JJ, Yousuf Z, Ouyang Z, Kennedy E, Lester PA, Martin T, et al. Anesthetic agents affect urodynamic parameters and anesthetic depth at doses necessary to facilitate preclinical testing in felines. Sci Rep 2020;10:11401.

24. Li WJ, Kim JM, Oh SJ. Effects of level of consciousness on urodynamic procedure in female cats. J Korean Med Sci 2011;26:803-6. 